McCrea's discussion of PCS as a uniquely neuropsychological disorder very nicely anticipates and dovetails with a recent proposal for designation of Cogniform Disorder and Cogniform Condition diagnoses (Delis \& Wetter, 2007). His treatment recommendations for PCS are straightforward and practical, but perhaps more powerfully asserted given Dr. McCrea's comprehensive and cohesive discussion of the empirical literature upon which the recommendations are based.

Mild Traumatic Brian Injury and Postconcussion Syndrome: The New Evidence Base for Diagnosis and Treatment is a jewel. It is rare in its accomplishment to so succinctly cover such an impressive amount of research.

\section{RECENT AND RELEVANT}

doi: $10.1017 /$ S1355617708080661

History of Psychiatry and Medical Psychology. Edwin R. Wallace, IV and John Gach (Eds.). 2008. Secaucus, NJ: Springer, 862 pp., \$89.95 (HB).

Bayesian Brain: Probabilistic Approaches to Neural Coding. Kenji Doya, Shin Ishii, Alexandre Pouget, and Rajesh P. N. Rao, (Eds.). 2007. Cambridge, MA: The MIT Press, 326 pp., \$54.00 (HB).

Treating Tourette Syndrome and Tic Disorders: A Guide for Practitioners. 2007. Douglas W. Woods, John C. Piacentini, and John T. Walkup (Eds.). New York: The Guilford Press, 287 pp., \$38.00 (HB).

\section{A Clinician's Handbook of Child and Adolescent} Psychiatry. Christopher Gillberg, Richard Harrington, and Hans-Christoph Steinhausen (Eds.). 2006. New York: Cambridge University Press, 751 pp., $\$ 100.00$ (HB).
Because of this, it will appeal to all levels of readers with an interest in MTBI and PCS. Old hands and students alike will find this book a concise and comprehensive reference text on the topic of MTBI and PCS. The added benefit of being able to obtain continuing education credit for books in the Oxford Workshop Series is a nice touch. I wholeheartedly recommend this book to all with an interest or need.

\section{REFERENCE}

Delis, D.C. \& Wetter, S.R. (2007). Cogniform Disorder and Cogniform Condition: Proposed diagnoses for excessive cognitive symptoms. Archives of Clinical Neuropsychology, 22, 589-604.

Handbook of Mathematical Cognition. Jamie I. D. Campbell (Ed.). 2005. New York, NY: Psychology Press, 211 pp., \$125.00 (HB).

Emotion Regulation: Conceptual and Clinical Issues, by Ad Vingerhoets, Ivan Nyklicek, and Johan Denollet. 2008. Secaucus, NJ: Springer, 246 pp., $\$ 89.95$ (HB).

Handbook of Emotion Regulation. James J. Gross (Ed.). 2006. New York, NY: Guilford Publications, 654 pp., \$85.00 (HB).

Emotions and Aggressive Behavior. Georges Steffgen and Mario Gollwitzer (Eds.). 2007. Seattle, WA: Hogrefe and Huber, 229 pp., US\$52.00; CAN\$ 68.00; €44.95 (HB). 